\title{
Liver Neuroendocrine Carcinoma
}

National Cancer Institute

\section{Source}

National Cancer Institute. Liver Neuroendocrine Carcinoma. NCI Thesaurus. Code C96787.

An extremely rare, aggressive, high-grade and poorly differentiated carcinoma with neuroendocrine differentiation that arises from the liver. 